\title{
Effect of Ursodeoxycholic Acid (USDA) on Indirect Hyperbilirubinemia in Neonates Treated with Phototherapy
}

\author{
Mehrdad Mirzarahimi, Manouchehr Barak*, Shima Sarfarazi Moghaddam and Efsaneh Enteshari Moghaddam \\ Department of Pediatrics, Faculty of Medicine, Ardabil University of Medical Sciences, Ardabil, Iran
}

*Corresponding author: Manouchehr Barak, Ardabil University of Medical Sciences, Ardabil, Iran

Received: 阱 April 29, 2019

Published: 恝 May 07, 2019

\begin{abstract}
Objective: To investigate the effect of USDA in the treatment of indirect hyperbilirubinemia of neonates. Study design: This randomized clinical trial was conducted on neonates with indirect hyperbilirubinemia whom were hospitalized at Ardabil city hospital. 100 newborns were enrolled in the study and randomly divided into two groups. The treatment group $(n=50)$ received $10 \mathrm{mg} / \mathrm{kg} /$ day divided $\mathrm{q} 12 \mathrm{~h}$ USDA in addition to phototherapy, while the control group $(\mathrm{n}=50)$ only received phototherapy. Total bilirubin levels were measured every 12 hours until reaching bilirubin below $10 \mathrm{mg} / \mathrm{dL}$. Also, duration of phototherapy and hospitalization in both groups were recorded. Data were analyzed in SPSS.21 using statistical methods.
\end{abstract}

Results: There was no difference in the mean of total bilirubin between treatment and control groups at baseline, 12, 24, 36, and 48 hours after admission.

Conclusions: Our study revealed that adding USDA to phototherapy in treating indirect hyperbilirubinemia of newborns had no preference to just phototherapy treatment.

Keywords: Phototherapy; Indirect Hyperbilirubinemia; Ursodeoxycholic Acid; Neonate

\section{Introduction}

Hyperbilirubinemia is the mostcommon cause of hospitalization among healthy and premature infants. Hyperbilirubinemiais prevalent and was seen in $60 \%$ of term neonates and $80 \%$ of preterm neonates [1]. Increase of indirect bilirubin is harmful and toxic to the brain and may lead to kernicterus which is a lasting and severe damage to the infant's nervous system [2]. Therefore, early treatment of hyperbilirubinemia is important. Typically, phototherapy is widely used as an effective method for the treatment of indirect hyperbilirubinemia in neonates, but has side effects such as fever, dehydration, diarrhea, maculopapular rash, sunburn baby syndrome, higher costs, time consuming and disruptions in the relationship between mother and child because of limiting the baby to incubators and covering his eyes. Studies have shown that in cases with bilirubin more than $20 \mathrm{mg} / \mathrm{dL}$, the power of phototherapy is decreased and reached to $10 \%-17 \%[3,4]$. So far, drugs such as oral activated charcoal, Metalloporphyrin, D-penicillamine, Phenobarbital and Clofibrate, have been used for the treatment of indirect hyperbilirubinemia $[5,6]$. Some studies showed that Phenobarbital has been effective in reducing indirect hyperbilirubinemia and length of phototherapy but has many side effects such as lethargy, reduction of breast-feeding, dehydration and neurological disorders [6,7]. Therefore, doing further studies in relation to medicines with fewer side effects seems necessary. Ursodeoxycholic acid (UDCA) is a bile acid that is widely used in the treatment of Cholestatic liver disorders. UDCA protect the liver against oxidative stress, prevents cell apoptosis and has main role in the stimulation of bile flow, and suppression of treating factors in immunological mechanisms [8]. Several studies have shown that the use of UDCA at a dose of 20-10 mg / kg / day is well tolerated by children and without any special side effects.9-12 Recently two studies have shown that UDCA, without any special side-effects, considerably reduces the time of reachingbilirubin to normal levels and the infants' hospitalization length $[9,10]$. The causes of the elevation of indirect hyperbilirubinemia may be physiological jaundice, Crigler-Najjar syndrome, Gilbert's syndrome, breast milk jaundice, blood group incompatibility of $\mathrm{Rh}$ and $\mathrm{ABO}$ blood groups 
and Glucose-6-Phosphate Dehydrogenase (G6PD) deficiency.This study aimed to investigate the effect of UDCA in reducing indirect hyperbilirubinemia of neonates treated with phototherapy.

\section{Materials and Methods \\ Type of Study and Patients}

This randomized clinical trial was conducted on 100 neonates with jaundice, who had received phototherapy in the Ardabil city hospital.

\section{Experiments}

All infants divided randomly in two intervention $(n=50)$ and control group $(n=50)$.The intervention group, in addition to phototherapy received UDCA at a dose of $10 \mathrm{mg} / \mathrm{kg} /$ day divided every 12 hours (UDCA, capsule $300 \mathrm{mg}$; provided by DrAdibi Company ,Tehran, Iran),with water and was used according to the weight of the infant and the recommended dose and the control group received only phototherapy. On the first day of hospitalization, Total and direct bilirubin, reticulocyte count, Coombs test, G6PD level, complete blood count ( $\mathrm{CBC}$ ), $\mathrm{RH}$, and blood group experiments were performed for both groups. Also, the total bilirubin level of each infant was measured every 12 hours until their bilirubin levels reach below $10 \mathrm{mg} / \mathrm{dL}$ and phototherapy stopped. The duration using of phototherapy for neonatal was calculated by the timer.

\section{Statistical Analysis}

Collected data entered in a checklist and analyzed using statistical methods and all statistical analysis were performed using SPSS.21. The $\mathrm{P}<0.05$ was considered statistically significant.

\section{Inclusion And Exclusion Criteria}

The inclusion criteria for the study were birth weights of 2500 to 4000 gr, breast-feed, gestational age of 38 to 41 weeks, age over 3 days old, total bilirubin level of 14 to $20 \mathrm{mg} / \mathrm{dL}$, and direct bilirubin level< $2 \mathrm{mg}$ / dL. Infants with ABO blood groups and RH incompatibility, G6PD deficiency, direct hyperbilirubinemia, septicemia and diseases leading to hyperbilirubinemia (Crigler-Najjarsyndrome, Gilbert's syndrome, hypothyroidism/ hyperthyroidism, liverdiseases, etc.), premature infants and the infants of diabetic mothers were excluded from the study.

\section{Ethical Approve}

Written informed consent was taken from infant's parents and this study was approved in ethics committee of university.

\section{Results}

Of all infants, 57\%were female and $43 \%$ were male. The mean birth weight of infants in treatment and control groups were $3079.8 \pm 371.33$ and $3231 \pm 367.3 \mathrm{~kg}$, respectively. The mean age of infants at the time of hospitalization in the treatment and control groups were $5.64 \pm 2.4$ and $6.3 \pm 2.6$ days, respectively. The mean duration of hospitalization in the treatment and control groups was 2/82 and 3/06 days, respectively. The mean duration of phototherapy was 53 and 59 hours in the treatment and control group. There was no significant difference in the average of total bilirubin of infants between treatment and control groups in different time periods (Table 1). There was no significant difference between the two study groups in terms of the mean total bilirubin of infants at the baseline, 12, 24, 36 and 48 hours after admission (Table 2). There was no significant difference in the mean duration of phototherapy and hospitalization between two groups (Table 3). There was no significant difference between boys and girls in term of the mean total bilirubin at baseline, 12, 24, 36 and 48 hours after admission. The average length of hospitalization and the duration of phototherapy in both groups was no significant in boys and girls.

Table 1: The mean of total bilirubin $(\mathrm{mg} / \mathrm{dL})$ in two groups by the time periods.

\begin{tabular}{|c|c|c|c|c|c|}
\hline Groups & Test 1 & Test 2 & Test 3 & Test 4 & p-value \\
\hline Intervention & $66 / 1 \pm 75 / 17$ & $15 / 2 \pm 34 / 15$ & $85 / 1 \pm 58 / 12$ & $58 / 1 \pm 65 / 10$ & $001 / 0$ \\
\hline Control & $06 / 2 \pm 34 / 17$ & $15 / 2 \pm 87 / 14$ & $80 / 1 \pm 61 / 12$ & $84 / 1 \pm 50 / 10$ & $001 / 0$ \\
\hline
\end{tabular}

Table 2: Comparison of the mean of total bilirubin $(\mathrm{mg} / \mathrm{dL})$ at different times in two groups.

\begin{tabular}{|c|c|c|c|}
\hline Groups & Intervention & Control & p-value \\
\hline At the time of hospitalization & $2.25 \pm 16.7$ & $2.25 \pm 16.7$ & 0.057 \\
\hline $12 \mathrm{~h}$ after hospitalization & $14.19 \pm 2.44$ & $14.19 \pm 2.44$ & 0.93 \\
\hline $24 \mathrm{~h}$ after hospitalization & $16.71 \pm 2.25$ & $16.71 \pm 2.25$ & 0.621 \\
\hline $36 \mathrm{~h}$ after hospitalization & $10.5 \pm 1.84$ & $10.5 \pm 1.84$ & 0.706 \\
\hline $48 \mathrm{~h}$ after hospitalization & $9.78 \pm 1.29$ & $9.78 \pm 1.29$ & 0.255 \\
\hline
\end{tabular}

Table 3: Comparison of duration of phototherapy and hospitalization time in two groups.

\begin{tabular}{|c|c|c|c|}
\hline Groups & Intervention & Control & p-value \\
\hline Phototherapy time(min) & $17.37 \pm 52.9$ & $14.75 \pm 59.56$ & 0.065 \\
\hline Time of hospitalization (day) & $0.77 \pm 2.82$ & $0.51 \pm 3.06$ & 0.07 \\
\hline
\end{tabular}

\section{Discussion}

Honar et al. in 2015 in a study, which investigated the effect of USDA plus phototherapy compared to single phototherapy in the treatment of indirect hyperbilirubinemia of neonates, showed that the speed of the reduction of bilirubin concentration in the group taking USDA was considerably high and the mean of required time for bilirubin concentration reduction below $10 \mathrm{mg} / \mathrm{dl}$ and, as a result, the mean of hospitalization in the experimental group was 
considerably less than the control group [10]. In this study, no complications were observed in infants caused by the use of USDA In this regard, Hassan et al [9]. In a similar study in 2015 examined the effect of USDA in reducing indirect hyperbilirubinemia in infants. The findings of their study revealed that using USDA along with phototherapy is more effective in bilirubin level reduction and quick treatment of infants compared to only phototherapy. In this study, also, no complications were observed in infants using USDA. Our study showed that the mean of bilirubin total in any of 12, 24, 36 , and 48 hours after hospitalization between two groups did not differ. It seems that use ofUSDAwith phototherapy does not lead to a more rapid decline in the average of total bilirubin compared to control group.So far, in the world, few studies have been conducted on the effect of USDA on indirect hyperbilirubinemia. Unlike the results of our study, the study Honar et al. and the study Hassan et al. showed that USDA caused a significant reduction in total bilirubin in neonates with indirect hyperbilirubinemia in the first 24 and 48 hours of hospitalization, respectively $[9,10]$. The findings of this study showed that the mean duration of phototherapy and length of hospitalization in the experimental group was lower than control group but not significant. Honar et al. and Hassan et al , in two studies showed that there was no significant difference in the reduction of total bilirubin, phototherapy and hospitalization time between male and female infants which in line with our study results.9-10 The findings of this study did not reveal any complication resulting from the use of USDA among infants. This finding was somewhat expected because most previous studies have shown that the consumption of USDA at a dose of 10-20 mg / kg / day are well tolerated by children without any special side effects [9-12]. Although the study ofKotb stated that using USDA (at a dose of $20 \mathrm{mg} / \mathrm{kg} /$ day) caused unwanted side effects such as diarrhea outbreaks among consumers.However, since USDAusein our study and other studies was short-term, approving and establishing a definite safety of this drug in infants require longterm follow-up [13].

\section{Conclusion}

Our study revealed that addingUSDA to phototherapy in treating indirect hyperbilirubinemia of newborns had no preference to single phototherapy treatment and it doesn't have a significant impact in reducing the duration of infants' phototherapy and hospitalization time. For future, doing multicenter studies, with a larger sample size and long-term follow-up are essential about possible side effects of this drug.

\section{Acknowledgment}

This study results financially supported by Ardabil University of medical science and authors would like to thanks all patients participated in our study. This study registered in the database of clinical trials with IRCT201611163127N3 Code.

\section{References}

1. Chen J, Sadakata M, Ishida M (2011) Baby massage ameliorates neonatal jaundice in full-term newborn infants. The Tohoku journal of experimental medicine 223: 97-102.

2. Watchko J (2012) Neonatal indirect hyperbilirubinemia and kernicterus. Averys Diseases of the Newborn. 9thed. Philadelphia: Elsevier Saunders.

3. (2004) American Academy of Pediatrics Subcommittee on Hyperbilirubinemia. Management of hyperbilirubinemia in the newborn infant 35 or more weeks of gestation. Pediatrics 114: 297-316.

4. Ip S, Chung M, Kulig J, O’Brien R (2004) An evidence-based review of important issues concerning neonatal hyperbilirubinemia. Pediatrics 114: e130-e53.

5. Moslehi MA, Pishva N (2007) Determination of effect of low dose Vs moderate dose of clofibrate on the decreasing in serum bilirubin level in the term healthy neonate. Iranian Journal of pediatrics 17: 108-112.

6. Dennery PA, Seidman DS, Stevenson DK (2001) Neonatal hyperbilirubinemia. N Engl J Med 344: 581-590.

7. Chawla D, Parmar V (2010) Phenobarbitone for prevention and treatment of unconjugated hyperbilirubinemia in preterm neonates: a systematic review and meta-analysis. Indian pediatrics 47: 401-417.

8. Méndez-Sánchez N, Brink MA, Paigen B, Carey MC (1998) Ursodeoxycholic acid and cholesterol induce enterohepatic cycling of bilirubin in rodents. Gastroenterology 115: 722-732.

9. Hassan AM, Abdulrahman A, Husain RH (2015) Effect of Ursodeoxycholic Acid in Lowering Neonatal Indirect Hyperbilirubinemia: A Randomized controlled trial. Merit Research Journal of Medicine and Medical Sciences 3: 402-405.

10. Honar N, GhashghaeiSaadiE, Saki F (2016) Effect of Ursodeoxycholic Acid on Indirect Hyperbilirubinemia in Neonates Treated with Phototherapy: A Randomized Trial. J Pediatr Gastroenterol Nutr 62: 97-100.

11. Balistreri WF (1997) Bile acid therapy in pediatric hepatobiliary disease: the role of ursodeoxycholic acid. Journal of pediatric gastroenterology and nutrition 24: 573-589.

12. Levine A, Maayan A, Shamir R (1999) Parenteral nutrition-associated cholestasis in preterm neonates: evaluation of ursodeoxycholic acid treatment. Journal of Pediatric Endocrinology and Metabolism 12: 54954.

13. Kotb MA (2008) Review of historical cohort: ursodeoxycholic acid in extrahepatic biliary atresia. J Pediatr Surg 43:1321-1327. 
This work is licensed under Creative Commons Attribution 4.0 License

To Submit Your Article Click Here:

Submit Article

DOI: $10.32474 /$ PAPN.2019.02.000136

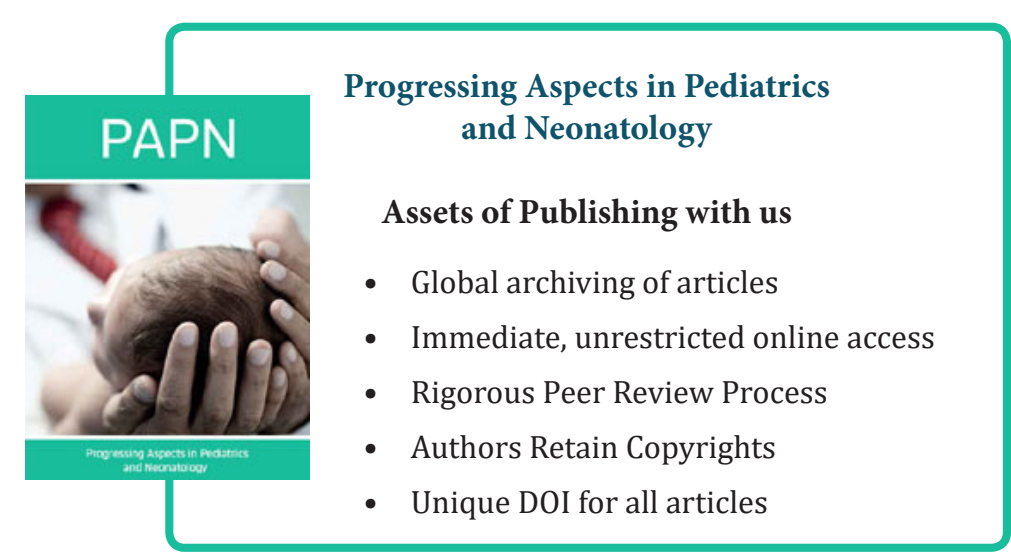

